\title{
Cryptococcal Meningoencephalitis
}

\author{
R. A. MARTIN, D. BATES, D. A. SHAW
}

British Medical fournal, 1975, 3, 75-76

\section{Summary}

A patient was admitted to hospital with an apparent psychiatric disturbance. When she became stuporous the cerebrospinal fluid was cultured but proved sterile. The latex test showed that serum was positive for cryptococcal antigens, and cryptococcal meningoencephalitis was diagnosed. Amphotericin $B$ was given but when she developed a toxic reaction it was replaced by flucytosine. She responded well to flucytosine alone and no side effects appeared on continued treatment. Cryptococcal meningitis may present as a psychiatric disturbance, and serological tests are invaluable aids to diagnosis.

\section{Introduction}

Cryptococcal infection of the central nervous system is rare in Great Britain in spite of the ubiquity of the causative organism. ${ }^{1}$ In 1973 six new cases were recorded at the Mycological Diseases Reference Laboratory in London; three of the patients were on corticosteroid therapy and two were suffering from Hodgkin's disease. ${ }^{2}$ Without treatment the disease runs a variable and usually fatal course, but with modern treatment most patients can be cured. ${ }^{3}$ Diagnosis is thus all-important and it may present difficulties both clinically and in the laboratory. The following case is reported to illustrate how in the absence of meningeal signs and with predominance of mental changes the disease may mimic a primary psychlatric disorder, and also to emphasize the importance of using several diagnostic laboratory tests.

\section{Case Report}

A 23-year-old school teacher first became ill in February 1973 when she complained of malaise, mild pyrexia, and repeated episodes of vertigo. Before this her health had been good, and she was an active sportswoman participating in parachuting and pot-holing. She was interested in animals and sometimes worked in a zoo during school holidays. The initial illness was attributed to influenza and she recovered spontaneously within a week. In June 1973 she developed fever, more persistent vertigo, fatigability, and mild anxiety. These symptoms persisted until September and then resolved.

In late October she married but soon afterwards she developed nausea, diarrhoea, and malaise. During November she noted poor concentration and intermittent blurring of vision, and at times her comprehension and verbal expression were impaired. Gradually she became retarded; there was a definite personality change and she took to her bed. She returned to her parents' home in December, by which time she was having visual hallucinations and great difficulty in expressing herself. She became very anxious and aggressive and developed insomnia. The pattern of her behaviour was quite bizarre and she seemed to be suffering from a psychiatric disturbance. On 13 December she was obviously confused and disorientated and was

Department of Neurology, Royal Victoria Infirmary, Newcastle upon Tyne NE1 4LP

R. A. MARTIN, M.D., Registrar (Present address: Mayo Clinic, Rochester, Minnesota, U.S.A.)

D. BATES, M.B., M.R.C.P., First Assistant

D. A. SHAW, M.B., F.R.C.P., Senior Lecturer in Neurology

admitted to the psychiatric department of her local hospital. Because she had fever $\left(38^{\circ} \mathrm{C}\right)$ and a mild right facial weakness the cerebrospinal fluid (C.S.F.) was examined and was found to contain $0.020 \times 10^{9} / 1$ lymphocytes, $200 \mathrm{~g} / 1$ protein, and $5.1 \mathrm{mmol} / 1(92 \mathrm{mg} / 100 \mathrm{ml})$ sugar; the pressure was normal

Viral encephalitis was provisionally diagnosed. Over the next two weeks her condition fluctuated with brief lucid intervals alternating with periods of disorientation and aggression. By the end of December she had deteriorated further and was transferred to our unit. On admission she was stuporous and pyrexial $\left(38^{\circ} \mathrm{C}\right)$ and had right facial weakness and bilateral extrapyramidal rigidity in her limbs. She had diminished pharyngeal reflexes and tonic oculocaloric responses. She was intubated and required ventilation.

The C.S.F. was re-examined 17 days after the first lumbar puncture. It was again under normal pressure and contained $0.001 \times 10^{2} / 1$ lymphocytes, $200 \mathrm{mg} / 1$ protein, and $4.3 \mathrm{mmol} / 1(78 \mathrm{mg} / 100 \mathrm{ml})$ sugar with a synchronous blood sugar of $5.1 \mathrm{mmol} / 1(92 \mathrm{mg} / 100 \mathrm{ml})$. No bacteria or fungi were seen in the fluid and all cultures were sterile. Blood and C.S.F. were sent for viral and fungal serological studies and 10 days later a report was received that the latex test had shown that the serum was positive for cryptococcal antigens. Further lumbar puncture was performed immediately and numerous cryptococci were seen (see fig.) though the C.S.F. still contained only $0.001 \times 10^{9} / 1$ lymphocytes and the protein and sugar values were again normal.

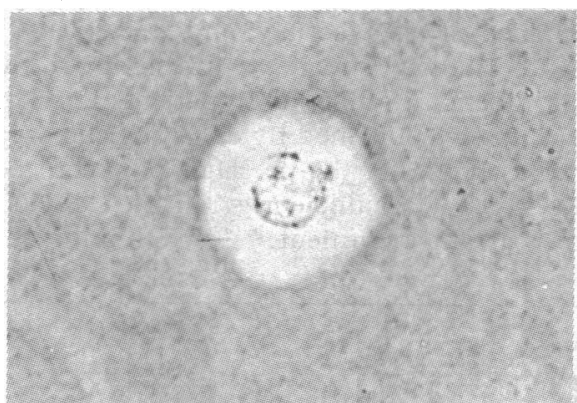

Cryptococcus neoformans in fresh specimen of C.S.F. treated with Indian ink, shown by phase contrast microscopy. $(\times 225$. $)$

Treatment was begun with amphotericin $B$ but the patient developed a severe toxic reaction and within 24 hours this drug was replaced with flucytosine $200 \mathrm{mg} / \mathrm{kg}$. The dose was later increased to $300 \mathrm{mg} / \mathrm{kg}$ to achieve satisfactory blood levels. Initially the flucytosine was given both intrathecally and by nasogastric tube and her condition began to improve almost immediately though cryptococci were still identified in the C.S.F. 48 hours later. Thereafter no further organisms were seen and none was cultured at any time. Further examinations showed serum and C.S.F. to be negative for cryptococcal antigen and antibody. The patient steadily recovered and by 9 February there were no residual clinical signs and she was discharged home. Over a years' follow-up her condition was entirely satisfactory and there were no side effects of treatment, which was continued. All investigations to exclude reticulosis, neoplasia, or an immune deficiency state proved negative.

\section{Discussion}

The source of infection in this as in most other cases of cryptococcosis remains uncertain but the patient might have been exposed to the organism while pot-holing or working in the zoo. The important clinical points illustrated by this history are the length of the prodromal illness and the emphasis in her symptoms on psychological disturbances. During the early 
part of her illness the patient was preparing for her wedding and her symptoms of malaise, fatigue, and dizziness were not unreasonably attributed to anxiety over this event. But immediately before admission her behaviour was very odd and was thought to signify a psychiatric disturbance until she became frankly stuporous. Though headache is generally regarded as the major presenting symptom of cryptococcal meningitis, ${ }^{4} 5$ several workers have emphasized the frequency of mental changes and some cases of frank psychosis have been reported. ${ }^{6} 7$

The other point we wish to emphasize relates to laboratory diagnosis. Changes in the normal constituents of the C.S.F. are variable and repeated attempts to show the organism by culture or India ink mount may be fruitless; this is especially true in patients with chronic meningitis. ${ }^{8} 9$ The only abnormality on initial C.S.F. examination in this patient was a mild pleocytosis, which had returned to normal by the second examination when brain function was severely disturbed. At both examinations routine search for yeasts using India ink preparations was unrewarding and cultures were likewise negative. The diagnosis was made on the basis of a positive latex test for cryptococcal antigen in serum and it was only on the third examination that cryptococci were seen in the C.S.F.

Hence, serodiagnostic tests should be performed in all patients in whom the possibility of cryptococcal infection is considered. Tests for the detection of anticryptococcal antibodies are not entirely satisfactor $y^{10}$ and greater specificity has been shown for the polysaccharide antigen in the latex agglutination $^{11}{ }^{13}$ and complement fixation tests. ${ }^{14}{ }^{16}$ Wolf et al. ${ }^{17}$ have recently shown successful results with an immunofluorescence test that uses the patient's serum antibody and the patient's cryptococcal organisms as the antigen. Nevertheless, the greatest diagnostic yield results from a search for both antigen and antibody simultaneously in serum and C.S.F.11121415 Thus, Kaufman and Blumer ${ }^{13}$ made a presumptive diagnosis of cryptococcal infection in $92 \%$ of 66 patients in whom the diagnosis was ultimately confirmed by culturing the organism.

Most studies show that the presence of cryptococcal antigen in serum or C.S.F. is sufficiently reliable evidence of active infection to warrant treatment. ${ }^{913} 15$ Diminution of antigen titre and the subsequent appearance of anticryptococcal antibodies during treatment indicate a favourable prognosis; but persistent or raised antigen titres may reflect continuing infection. ${ }^{16}$ The only disadvantage is that processing the serological tests takes some time. Nevertheless, these tests are invaluable in cases in which the disease is suspected clinically but organisms are not demonstrable in the C.S.F.

We thank Dr. J. Kennedy and Dr. F. L. Constable of the department of microbiology, Royal Victoria Infirmary, for helpful advice and the photograph of the organism; Dr. D. Davies of the London Hospital for blood estimations of 5-fluorocytosine; and the Mycological Diseases Reference Laboratory for serological testing.

\section{References}

1 Partridge, B. M., and Winner, H. I., Lancet, 1965, 1, 1060.

2 Epidemiology, British Medical fournal, 1974, 1, 252.

${ }^{3}$ Diamond, R. D., and Bennett, J. E., Annals of Internal Medicine, 1974, $80,176$.

${ }^{4}$ Butler, W. T., et al., New England fournal of Medicine, 1964, 270, 59.

${ }^{5}$ Edwards, V. E., Sutherland, J. M., and Tyrer, J. H., fournal of Neurology, Neurosurgery and Psychiatry, 1970, 33, 415.

${ }^{6}$ Cox, L. B., and Tolhurst, J. C., Human Torulosis, Australia, Melbourne University Press, 1946.

${ }^{7}$ Fetter, B. F., Klintworth, G. K., and Hendry, W. S., Mycoses of the Central Nervous System, Baltimore, William and Wilkins, 1967.

${ }^{8}$ Emmons, C. W., Binford, C. H., and Utz, J. P., Medical Mycology, Philadelphia, Lea and Febiger, 1970.

${ }^{9}$ Goodman, J. S., Kaufman, L., and Koenig, M. G., New England fournal of Medicine, 1971, 285, 434.

10 Seeliger, H. P. R., Systemic Mycoses, London, Churchill, 1968.

11 Bloomfield, J., Gonlon, M. A., and Elmendorf, D. F., Proceedings of the Society for Experimental Medicine, 1963, 114, 64.

12 Gordon, M. A., and Vedder, D. K., Fournal of the American Medical Association, 1966, 197131.

${ }^{13}$ Kaufman, L., and Blumer, S., Applied Microbiology, 1968, 16, 1907.

14 Neill, J. M., Sugg, J. Y., and McCauley, D. W., Proceedings of the Society for Experimental Biology and Medicine, 1954, 77, 775.

15 Bindschadler, D. D., and Bennett, J. E., Annals of Internal Medicine, $1968,69,45$.

${ }_{16}$ Walter, J. E., and Jones, R. D., American Review of Respiratory Diseases, $1968,97,275$.

17 Wolf, P., Russell, B., and Jacobs, P., fournal of the American Medical Association, 1973, 226, 1009.

\section{SHORT REPORTS}

\section{Bacterial Endocarditis after Insertion of Intrauterine Contraceptive Device}

Bacterial endocarditis developed in a young woman soon after the insertion of an intrauterine contraceptive device (I.U.D.). It is suggested that the two events may be related.

\section{Case Report}

A 24-year-old schoolteacher of previous good health was admitted to the North Middlesex Hospital with pyrexia of unknown origin. Six weeks previously an I.U.D. (Gravigard; Searle and Co. Ltd.) had been inserted, and at the time the cervix appeared normal. Two weeks later she developed a persistent offensive yellow vaginal discharge. Two weeks before admission she had suffered attacks of shivering and joint pains. She appeared ill and was feverish. Though three splinter haemorrhages were found the heart appeared to be normal. Vaginal examination showed a profuse green discharge arising from the cervix. The adnexa were tender. The I.U.D. was removed and a cervical swab taken which later grew Streptococcus viridans, Staphylococcus albus, and a diphtheroid. A penicillin-sensitive Str. viridans was isolated from blood cultures four days after admission. At that time an early diastolic murmur was heard, endocarditis was diagnosed and treatment with parenteral penicillin was started (10 MU daily).

During six weeks of treatment she developed cardiomegaly and orthopnoea. Cardiac catheterization showed severe aortic incompetence. The left ventricular end-diastolic pressure was $27 \mathrm{~mm} \mathrm{Hg}$. Left ventriculography showed greatly impaired contractility, the ejection fraction measuring $49 \%$. An aneurysm of the left sinus of valsalva was seen. Four weeks after penicillin was stopped the aortic valve was replaced under cardiopulmonary bypass at St. Bartholomew's Hospital. The aortic valve was bicuspid, with fusion of the left and right coronary cusps. An aneurysm 2 by $1 \mathrm{~cm}$ was found just above the origin of the left coronary cusp. The mitral subvalvar apparatus, inspected through the aortic root, appeared normal. The aortic valve was excised and replaced with a No. 9 Starr-Edwards Silastic ball valve. Bypass was discontinued but the heart required intensive inotropic support, and despite counterpulsation with a balloon pump the patient's condition deteriorated. She died 30 hours after returning from the theatre.

\section{Discussion}

Clinically this patient developed an intrauterine infection associated with the insertion of the I.U.D. Since a mixed growth was obtained from the cervical swab, and since Str. viridans is a vaginal commensal, there is only suggestive evidence that endocarditis was caused by inserting the device four weeks before the development of symptoms. The swab, however, was taken from the cervix rather than the vagina. The culture of Str. viridans from the cervix was discarded before it was realized that the patient had endocarditis; thus a comparison of the organism with the streptococcus isolated by blood culture was not possible.

Though intrauterine infection after the insertion of an I.U.D. is thought to be rare in Britain, ${ }^{1}$ investigators in the U.S.A. have reported an incidence of $2.5 \%$ in the first year. ${ }^{2}$ There has been one previous report of endocarditis after the insertion of a Lippes I.U.D. ${ }^{3}$ The timing of surgical intervention in patients with bacterial endo- 